\title{
Reflexiones acerca de la responsabilidad social empresarial desde su dimensión laboral
}

\section{Dra. Isabel C. Jaramillo Arango}

Abogada de la Universidad Pontificia Bolivariana (Colombia). Doctora en Derecho de la Universidad Castilla La-Mancha (España). Colaboradora de la UNED en los Programas de Doctorado y Maestría del Derecho del Trabajo en el curso de Trabajo Decente y Productividad y Derecho de Trabajo, Empresas Multinacionales y Comercio Internacional, respectivamente. Correo electrónico: isajaramillo111@racsa.co.cr

Recibido: Enero 2015 • Aceptado: Febrero 2015

\section{RESUMEN}

A pesar de que no existe una definición unívoca de la Responsabilidad Social Empresarial (RSE), se ha adoptado la que se formuló en el llamado "Libro Verde" de la Unión Europea, en el año 2001. En este sentido, la RSE debe corresponder a la actitud con que la empresa afronta las diferentes demandas o exigencias que existen en la sociedad a la cual pertenece, exigencias que constituyen un plus normativo que va más allá de las obligaciones legales, sociales, ambientales y económicas. Ese plus normativo genera ventajas competitivas y beneficios sociales adicionales a los económicos, las cuales se traducen en bienestar para sus diferentes grupos de interés. Además, mejora la imagen y reputación que se proyecta y construye por parte de la empresa hacia el colectivo de ciudadanos. Esto le permite fortalecer el posicionamiento e identidad de su marca y productos; y al mismo tiempo beneficia su propio prestigio. Al ser la RSE de carácter voluntario se sugiere que los Gobiernos y actores sociales adopten medidas concretas para su desarrollo, tales como leyes, incentivos fiscales, investigación universitaria, entre otros.

Palabras clave: Grupos de interés (stakeholders), responsabilidad social empresarial interna y externa, principios orientadores, retos y desafíos.

\section{ABSTRACT}

While there is not a clear definition of the Corporate Social Responsibility (CSR), it has been adopted the statement by the so-called "Green Book" of the European Union (2001). In this sense, CSR must correspond to the attitude with which the company faces different demands or requirements from the society to which it belongs, requirements that constitute a policy plus that goes beyond the legal, social, environmental and economic obligations. This normative plus generates competitive advantages and additional social benefits to economic ones, that bring about well-being for its different stakeholders, in addition to image and reputation that is projected and constructed by the company towards the group of citizens and allow to strengthen the positioning and allow, while adding to its own prestige. To be the CSR on a voluntary basis, it is suggested that Governments and social actors take concrete steps for its development, such as laws, tax incentives, university research, among others.

Key words: stakeholders, internal and external corporate social responsibility, guiding principles, challenges. 


\section{Generalidades}

Es sorprendente como en los últimos años se ha despertado un gran interés acerca de la Responsabilidad Social Empresarial (RSE en adelante) a nivel de las propias empresas, ONG, sindicatos, universidades, gobiernos, entre otros.

La RSE tiene que ver directamente con los procesos de globalización y el protagonismo que, desde varias épocas, vienen desarrollando las empresas transnacionales (ETN) como sujetos importantes de un poder económico y comercial único que las hace ser una fuerza, según Baylos (2009: 43), hegemónica a nivel supranacional ${ }^{1}$. Este poder que se ha decantado poco a poco dentro y fuera de los espacios del Estado-nación.

Actualmente se tiene un Estado-nación débil frente a las decisiones que se toman en los niveles (nacional y supranacional), ya que estos han tenido que adaptarse a las nuevas estrategias y políticas que marca el mercado y el capital en la era de la globalización. Los Estados se han ido acoplando a nuevas formas de paliar los déficits que tienen en el cumplimiento efectivo de los derechos laborales fundamentales y en el empleo. La mayoría de las estrategias empleadas por los gobiernos han generado una multitud de reformas laborales con tendencia a la baja, como son los casos de Argentina, Colombia y otros países de Latinoamérica, quienes llevaron a cabo reformas que flexibilizaron los mecanismos de contratación, jornadas y despido, produciendo a la par un debilitamiento de una de las instituciones más importantes en el ámbito del derecho colectivo, la negociación colectiva.

Este debilitamiento es consecuencia de esfuerzos de los Estados para eliminar cualquier rigidez característica de las normas laborales, con el fin de crear más empleo formal y decente. Lamentablemente, el resultado no ha sido el

1. Véase, BAYLOS. A., Un instrumento de regulación: Empresas transnacionales y acuerdos marco globales, Cuadernos de Relaciones Laborales, "La responsabilidad social empresarial en Europa y las corporaciones transnacionales, Vol.27, núm.1. UCM, 2009. esperado, ya que se ve ahora -muchos años después- es que se aumentaron los índices de empleo informal, precarización y desempleo. Hoy los trabajadores han tenido que soportar y convivir con la inestabilidad en el empleo, inseguridad en los ingresos, altos índices de rotación, escasa protección social, entre otros. Dichas reformas, en algunas circunstancias, han reñido con las garantías propias del derecho de trabajo causando pérdida de efectividad en las mismas -en el ámbito nacional-, modelo que ha perdurado hasta el día de hoy.

La globalización ha suscitado nuevos escenarios productivos que le han permitido a las empresas crear espacios para la construcción de reglas, mediante la concretización de principios y normas de categoría soft law ${ }^{2}$, que ayudan y propician la autorregulación privada y voluntaria del ámbito empresarial, con el fin de prevenir los riesgos que ellas mismas generan como consecuencia de sus actividades productivas y de los impactos negativos que a nivel económico, social y medioambiental pudieren presentarse.

El reto que tienen las empresas es hacer realidad, desde la acción y la práctica, una visión positiva de la RSE. Es decir, alcanzar una buena relación con sus grupos de interés -stakeholders-, en la cual haya participación y comunicación permanente, la vivencia de valores traducida en el respeto de las reglas de juego de todos y cada uno de ellos, logrando desde la cotidianidad de la empresa una acción plenamente responsable ante la sociedad, actuando con coherencia frente a los valores y principios que ellas mismas promulgan en todas sus actuaciones y decisiones, además de la rendición de cuentas que deben hacer de su obrar, que es lo que hoy se le conoce como accountability. Es decir:

(...) la oportunidad de configurar un proceso de aprendizaje que expresa y reelabora la visión de futuro de una empresa", que "define el tipo de empresa que se quiere construir y la contribución que

2. Soft law, hace alusión a las normas que carecen de fuerza vinculante o de eficacia jurídica. 
se pretende que dicha empresa haga a la sociedad. (Lozano: 2009: 155)

Hoy para algunas empresas, la RSE representa un simple escudo, o es utilizada como una estrategia defensiva o preventiva ante las críticas que reciben por los impactos socialmente negativos generados en sus procesos productivos. Estos han trascendido las fronteras nacionales en los últimos años, al tener la posibilidad de trasladarse de un lugar a otro sin ningún tipo de limitación, creando cadenas de producción complejas ${ }^{3}$.

En la mayoría de estas cadenas no hay control efectivo, ni medición de los impactos económicos, sociales y medioambientales de las acciones llevadas por ellas en sus propios procesos de producción. Hecho que se ha visto con gran preocupación por parte de algunos organismos internacionales, que desde la década de los 70, y ante el impulso de las empresas multinacionales, hicieron que se adoptaran dos declaraciones específicas por parte de la Organización para la Cooperación y Desarrollo Económico (OCDE) en 1976, y la Organización Internacional del Trabajo (OIT) en 1977. Ambas con el objetivo de lograr un mayor respeto hacia las condiciones

3. CERFEDA, W., "El sindicalismo Europeo ante la responsabilidad social empresarial", Cuadernos de información Sindical. "La dimensión laboral de la responsabilidad social de las empresas, núm.63, 2005, pág.14: "Hoy día el funcionamiento del mercado ha cambiado profundamente. La demanda, su variabilidad ha rediseñado el proceso productivo, descomponiéndolo. La flexibilidad de la producción y de la prestación supone el cuadro de referencia constante dentro del cual debemos actuar. La cadena de valor se ha alargado enormemente. Reconstruir la trazabilidad del producto desde su diseño hasta su comercialización supone a menudo un ejercicio difícil, cuando no imposible. La maraña que forman el core business y los diversos segmentos de suministro, la subcontratación, el autsourcing, las contratas de diversos niveles, hasta las zonas de trabajo gris o negro, configura a menudo todo el complejo o recorrido por el que un producto debe atravesar. Sin embargo, es a lo largo de esta cadena de valor donde a menudo se quiebra la cadena de los derechos. Los derechos de los trabajadores -pero también el respeto hacia las reglas y las leyespierden fuerza a medida que se desgranan todos y cada uno de los eslabones de la cadena". sociales de los trabajadores, definiendo la responsabilidad propia de las empresas, entre ellas la responsabilidad social. Este se constituye como un primer intento por parte de los diferentes grupos de interés por encontrar fórmulas que permitieran establecer en el actuar de las empresas estándares justos en materia de derechos humanos, entre ellos los laborales.

Sin duda, los Estados-nación no han tenido un fuerte protagonismo en el campo de la RSE, ya que la iniciativa proviene de la empresa privada transnacional, de algunas instituciones internacionales y de grupos empresariales globales que se apropian de espacios de regulación mediante la creación de nuevas formas privadas de autorregulación, que afectan a sus diferentes stakeholders o grupos de interés. Esta autorregulación que puede verse traducida en pactos, códigos o acuerdos privados, donde este tipo de responsabilidad es ejercida por quienes dirigen la empresa y detentan el poder, sin la participación de otros entes públicos o de naturaleza mixta que pudieren influir en la misma toma de decisiones y en los procesos.

La RSE ha logrado insertarse en las agendas políticas de organismos e instancias supranacionales y hoy se contempla un diálogo más amplio y profundo en materias como la misma gobernanza mundial, la transparencia, medio ambiente y el desarrollo sostenible o en el comportamiento de las empresas hacia el cumplimiento de los derechos fundamentales del trabajo. Ha sido importante el aporte y protagonismo que ha tenido la sociedad civil; especialmente las ONG, movimientos sociales, sindicatos y organizaciones de activismo social que han impulsado hasta la actualidad campañas de presión política frente a algunas actividades irresponsables de las empresas transnacionales, convirtiéndose en protagonistas activos de la salvaguarda de derechos humanos, apoyados por mecanismos de gobernanza a nivel mundial.

Este es el despertar de una nueva conciencia de respeto por parte de las empresas en el cumplimiento de los derechos humanos y sociales, con denuncias y campañas formuladas contra 
actividades empresariales poco responsables. Las denuncias hechas por algunas organizaciones civiles se han orientado a la crítica en el lugar donde se estructuran las reglas que regulan el comercio internacional, como es el Acuerdo General sobre Aranceles Aduaneros y Comercio (GATT) y la Organización Mundial del Comercio (OMC). En estas normas reguladoras del comercio internacional, no hay referencia alguna al respeto de los derechos sociales, hecho que es lamentable hasta el día de hoy, puesto que lo que se desea es conseguir una homogeneización en los estándares laborales a nivel mundial en el intercambio de bienes y servicios en la era de la globalización y un equilibrio entre la gran brecha que separa el mundo económico del social.

Los Estados-nación deben entender que su papel es importante y esencial en la construcción política y social que la RSE necesita. El fenómeno de la globalización ha hecho ver la necesidad de la creación de alianzas público-privadas, para la ejecución de proyectos que generen impactos positivos para la comunidad y que persigan su bienestar.

Cada comunidad tiene sus propias peculiaridades, pero también es cierto que muchas de ellas se encuentran en un estado de indefensión por razones económicas, políticas, geográficas o de cualquier otra, por lo que es conveniente que los Estados se involucren de forma activa y que desde sus políticas públicas, la RSE tenga un papel preponderante y decisorio. Lo anterior toma más importancia si se considera que el Estado es un ente legitimado democráticamente para articular las reglas que determinan una RSE más igualitaria, más equitativa, más cohesionadora y más justa. Es decir, esta debe estar al alcance de la ciudadanía, de las comunidades y de las poblaciones. La RSE no debe ser percibida como una "exclusividad" reservada para un grupo, club o élite muy reducido con capacidad para incidir en decisiones que afectan derechos económicos, sociales y ambientales de alcance global.

La RSE, además, no puede concebirse como un accesorio que esté en la periferia de las estrategias de la empresa. Por el contrario, debe situarse en el centro de quehacer para generar una cultura de respeto hacia todo lo que la rodea, porque -de no ser así- la RSE puede convertirse en marketing social. En otras palabras, sería una simple herramienta que le permite mostrar a la empresa una imagen idílica que no corresponde a la realidad, pero que, con acciones puntuales de filantropía en diversos aspectos crea una imagen positiva, ante sus grupos de interés, quedando en la memoria o en el subconsciente colectivo de éstos, pero sin transformaciones sociales importantes. La RSE debe influir en la empresa de modo transversal, en cada una de las dimensiones internas y externas y en cada uno de los ámbitos en los que se relaciona con sus stakeholders en el económico, social y medioambiental, donde se vivencien y se lleven a la práctica con coherencia valores corporativos complementados con contenidos de RSE.

La RSE deber corresponder a esa actitud con que la empresa afronta las diferentes demandas o exigencias que existen en la sociedad a la cual pertenece, exigencias que constituyen un plus normativo que va más allá de las obligaciones legales, sociales, ambientales y económicas. Ese plus normativo genera ventajas competitivas y beneficios sociales adicionales a los económicos, que se traducen en bienestar para sus diferentes grupos de interés, además de la imagen y reputación que se proyecta y construye por parte de la empresa hacia el colectivo de ciudadanos y que le permiten fortalecer el posicionamiento e identidad de su marca y productos, siendo positivo para su propia reputación.

Puede afirmarse que la RSE ha estado presente en Europa desde finales del siglo XIX, época durante la cual algunos empresarios o dueños de empresas, movidos por corrientes filosóficas y religiosas, llevaron a cabo acciones sociales con el fin de lograr un mayor bienestar para sus trabajadores y sus familias. A inicios del siglo XX, las obras filantrópicas de algunos empresarios - grandes donaciones destinadas a causas sociales-, se convirtieron en prácticas que han sido emuladas hasta la actualidad por parte de algunas empresas interesadas en desarrollar su acción social. 
A mediados del siglo XX, la RSE adquiere su dimensión moderna, cuya denominación es acuñada en los Estados Unidos. En 1953, Howard Bowen publica su obra: Las responsabilidades sociales del empresario (Social Responsabilities of the Businessman), donde plantea la necesidad de que los administradores actúen y tomen decisiones según los principios y valores éticos de la sociedad. Diez años después, en 1963, Joseph W. McGuire expone que la RSE debe ir más allá de las obligaciones legales y económicas que tiene la empresa; muy al contrario de lo expuesto por Milton Friedman, quien hacia los años setenta, enfatizó que la única responsabilidad que tenían los administradores o gerentes y trabajadores de las empresas era la de obtener cada día mayores beneficios para sus accionistas o propietarios. En los años setenta, la fuerza económica y el poder que toman las empresas multinacionales hacen que estas sean cuestionadas por sus impactos sociales, económicos y ambientales, derivados de sus operaciones productivas, y de la percepción del comportamiento de las mismas en el entorno nacional.

A pesar de esto, es hasta finales del año 1999 que el entonces Secretario de las Naciones Unidas, Kofi Annan, propuso en la conferencia llevada a cabo en Davos, Suiza, crear un gran Pacto Mundial y adoptar un "rostro más humano" para enfrentar los desafíos impuestos por la globalización y el mercado mundial. Es así como la RSE pasa a convertirse en una estrategia que las Naciones Unidas coordinan con el sector privado, con el fin de hacer que las empresas privadas se comprometan a cumplir y acoger voluntariamente los 10 principios basados en el respeto de los derechos humanos, laborales, medioambientales y la lucha contra la corrupción; principios inspirados en la misma Declaración Universal de Derechos Humanos, promulgada en el año 1948.

La fase operacional del UN Global Compact se inició en julio del año 2000 en la sede de la Organización de las Naciones Unidas (ONU) en Nueva York. Esta fecha marca el inicio y la creación de lo que se denominó - Global Compact-organismo encargado dentro del sistema de la ONU de los temas y actividades que tienen que ver con la RSE. Las empresas que se adhirieren a él asumen el compromiso, dentro de sus estrategias de negocio, de llevar a cabo prácticas responsables en materia económica, social y ambiental.

La RSE aparece por primera vez en la Unión Europea (UE) en el año 1999, en la Resolución del Parlamento Europeo sobre la Adopción de normas por la Unión Europea para las empresas europeas que operan en países de desarrollo: hacia un código de conducta europeo ${ }^{4}$. El propósito de dicha resolución era que las empresas se comprometieran a respetar los derechos humanos, sociales y ambientales a nivel global; es decir, dentro y fuera de la UE.

Es así como para el año 2000, en la Cumbre de Lisboa, la RSE se convirtió en una prioridad, al punto de que ha sido un tema importante en los siguientes Consejos Europeos. La idea era incorporarla en las estrategias sobre empleo, cohesión social, competitividad, innovación y desarrollo sostenible. Para el año 2001, la Comisión aprobó la Comunicación sobre el Libro Verde, Fomentar un marco europeo para la responsabilidad social de las empresas 5 , la cual se ha constituido en un marco general que les ha servido a los Estados miembros para sentar las bases nacionales en la materia.

El Libro Verde es parte de un conjunto de disposiciones normativas no vinculantes -soft lawde la UE, encaminadas a reforzar su intención de asumir un liderazgo a nivel global en el tema. Para ello, se desarrollan programas específicos en los cuales la UE tiene presencia, o bien sus empresas se encuentran deslocalizadas en diferentes países a nivel mundial. Esto explica el interés de la UE -como parte de su política comercial con

4. PARLAMENTO EUROPEO, Resolución sobre la Adopción de normas por la Unión Europea para las empresas europeas que operan en países en desarrollo: Hacia un código de conducta europeo. A4-0508/1998, Estrasburgo, 15-1-1999.

5. COMISION DE LAS COMUNIDADES EUROPEAS, Libro Verde, Fomentar un marco europeo para la responsabilidad social de las empresas [COM (2001) 366 final], Bruselas, 18.7.2001. 
terceros países- por ofrecer preferencias arancelarias a los países que suscriban acuerdos comerciales y en donde se cumplan los Convenios internacionales esenciales de Naciones Unidas y de la OIT, sobre derechos humanos y laborales.

El lograr este tipo de acciones contribuye a una gobernanza social internacional, pues genera una nueva cultura de cumplimiento de derechos, normas mínimas sociales, ambientales y económicas en los acuerdos multilaterales o bilaterales que la UE suscriba con los respectivos países. Cabe destacar que en los documentos de la UE se ratifica la naturaleza voluntaria de la RSE y su normativa no vinculante, así como la importancia del ejercicio de las buenas prácticas externas e internas desarrolladas en las políticas de gestión empresarial hacia los recursos humanos. Se supone, además, que en ese marco es necesario un diálogo social permanente, que se traduzca en acuerdos claves para alcanzar los objetivos planteados en las estrategias europeas y en la construcción de una RSE más sólida y concreta. A raíz de ello, la Comisión Europea (CE) insiste en la promoción de la RSE como base para los distintos procesos en materia social en aspectos como: la negociación colectiva transnacional y el aumento de competencias para los interlocutores sociales con una efectiva capacidad de acción, en el que se logren soluciones rentables para las partes involucradas.

Es importante señalar que hasta ahora no existe un consenso mundial respecto a la definición de lo que es la RSE, pero algunos autores y expertos en el tema adoptan la definición que formuló la UE en el año 2001, en la Comunicación de la CE, denominada Libro Verde, Fomentar un marco europeo para la responsabilidad social de las empresas. En dicha comunicación se indicó que la RSE es "la integración voluntaria por parte de las empresas, de las preocupaciones sociales y medioambientales en sus operaciones comerciales y sus relaciones con sus interlocutores". Esta definición fue modificada en la última Comunicación sobre RSE, Estrategia renovada de la UE para 2011-2014 sobre la responsabilidad social de las empresas ${ }^{6}$, aprobada en el mes de octubre del
2011, en donde pasa a concebirse como: "la responsabilidad social de las empresas por su impacto en la sociedad".

La misma UE aboga para que se respete la legislación aplicable y los convenios colectivos entre los interlocutores sociales como requisito previo a la RSE. Además, se defiende la existencia de una estrecha colaboración con las partes interesadas en el proceso destinado a integrar las preocupaciones de los consumidores en sus operaciones y en sus estrategias, maximizando la creación de valor compartido para sus propietarios/accionistas y para los demás grupos de interés incluyendo a la sociedad en general. Asimismo, se busca identificar, prevenir y atenuar las posibles consecuencias adversas.

\section{Los grupos de interés o stakeholders}

No se debe olvidar la importancia y poder que ejercen los distintos grupos de interés, o stakeholders ${ }^{7}$, en relación con la empresa, centro donde se toman decisiones que los afectan indistintamente. La RSE plantea su esencia a partir de la realización de su objeto social. Uno de sus aspectos principales que debe tomarse en cuenta es entonces el nexo que tiene la empresa con sus diferentes stakeholders, vínculo que debe estar siempre en el centro de sus estrategias, haciéndoles partícipes de su cultura empresarial.

La conciliación de expectativas con los grupos de interés hace que la empresa se involucre

6. COMISION DE LAS COMUNIDADES EUROPEAS, Comunicación de la Comisión, "Estrategia renovada de la UE para 2011-2014 sobre la responsabilidad social de las empresas [COM (2011) 681 final], Bruselas 25.10.2011.

7. COMISION DE LAS COMUNIDADES EUROPEAS, Libro Verde, Fomentar un marco..., cit., pág. 12: "lejos de circunscribirse al perímetro de las empresas, la responsabilidad social se extiende hasta las comunidades locales e incluye, además de los trabajadores y accionistas, un amplio abanico de interlocutores: socios comerciales y proveedores, consumidores, autoridades públicas y ONGs defensoras de los intereses de las comunidades locales y el medio ambiente". 
en sus necesidades y diseñe fórmulas que faciliten una mayor integración de los mismos, con estándares respetuosos en lo social, medioambiental y económico. Sólo una empresa que sea capaz de llevar en sus estrategias las diferentes percepciones, intereses y preocupaciones de los grupos de interés que la rodean, puede lograr cimentar las bases de una nueva empresa ciudadana, ${ }^{8}$ que logre de manera real y eficaz equilibrar los derechos y deberes de los implicados, así como un mejor aprovechamiento del capital y de las utilidades de la empresa.

En lo que se refiere al concepto de grupo de interés o stakeholders, existe un consenso bastante amplio sobre el mismo y hace referencia a todas aquellas personas o grupos de personas que resultan afectados por las decisiones, actuaciones y actividades de la empresa en el presente o en el futuro.

Los stakeholders pueden, en un momento determinado, crear alianzas que permitan desarrollar nuevas competencias e incidan en el buen funcionamiento de la empresa. En la literatura propia del tema algunos autores consideran prudente hacer una clasificación de los mismos, así: statekholders ${ }^{9}$ internos, en los que estarían los trabajadores, accionistas o propietarios de la empresa y los stakeholders externos: los clientes,

8. LOZANO. J., La empresa ciudadana como empresa..., cit., pág.22: "Cuando hablamos de una empresa ciudadana nos limitamos a constatar una tendencia que comporta un notable cambio de perspectiva; una tendencia que implica la asunción de que la empresa no constituye solamente una institución económica, sino también una institución social. Así pues se trata de gestionar, dirigir y valorar las empresas a partir de la integración de todas las dimensiones que las configuran".

9. Ibídem, págs. 71 y 72: "la identificación de los stakeholders es el resultado de cuatro parámetros:

a) La calidad de la relación con los stakeholders: con qué amplitud de miras se identifica la relación? A este respecto, se han utilizado tres criterios graduales en los que, como se puede comprobar, aunque la identificación de un stakeholders es estrictamente relacional, lo que se pretende ampliar en esta gradación es la capacidad de la empresa para tener en cuenta la perspectiva adoptada por su interlocutor en esa relación. la comunidad, ONG, contratistas, proveedores, entre otros.

\section{Las dimensiones de la RSE}

\section{Interna}

Es en esta dimensión ${ }^{10}$ donde la empresa por sí misma, y con la autonomía que la caracteriza, realiza buenas prácticas en materia laboral y

Estrecho: todos los grupos que son vitales para la supervivencia y el éxito de la empresa.

Amplio: cualquier grupo o individuo que puede afectar o verse afectado por la empresa.

Aquellos individuos o grupos que dependen de la empresa para alcanzar sus objetivos o aquellos de los que la empresa depende para su propia existencia.

b) La relevancia de la relación con los stakeholders en la actividad de la empresa.

Primarios: indispensables para las operaciones de la empresa (inversores, empleados, clientes, proveedores...).

Secundarios: con influencia, pero sin involucración directa de las operaciones de la empresa (gobiernos, medios de comunicación, organizaciones sociales, ONG...). c) Las oportunidades de aprendizaje que la relación con los stakeholders generan para la empresa. En este sentido, se ha puesto de relieve que los stakeholders:

Son fuente de expectativas y de demandas en relación con lo que se espera de la empresa.

Contribuyen de manera imprescindible a las actividades de la empresa.

Reciben los afectos y las consecuencias de las actividades de la empresa.

Valoran y evalúan si la contribución de las empresas puede considerar aceptable.

Se hallan involucrados en todo el proceso de producción de la empresa.

d) Lo que está en juego en la relación, sean intereses, exigencias legales, derechos.

10. En el ámbito interno de la RSE, son muchas las practicas que se pueden llevar a cabo por parte de las empresas, las cuales favorecen las relaciones laborales, como por ejemplo: condiciones laborales de los trabajadores, formación, respeto de los derechos humanos y laborales en la empresa principal y filiales, diálogo social con los interlocutores sociales, en los que se les dé una debida participación en las políticas y decisiones que afectan a los trabajadores, posibilitar el acceso de personas discapacitadas a la empresa, lograr mediante la prevención de los riesgos laborales una disminución de siniestralidad y tener como meta el cero accidentes, entre otros. 
social que afectan de forma directa al conjunto de trabajadores y sus representantes.

Se debe crear un marco general para lograr una mejor gestión de los trabajadores de la empresa, de manera que determine las líneas base para la formulación de prácticas responsables en cada uno de los temas que se relacionan con la gestión humana empresarial. Es aquí donde la RSE puede enriquecer, de una forma más profunda, los contenidos de los mismos y contribuir a mejorar las condiciones de los trabajadores y de sus familias ${ }^{11}$.

Las partes, por el poder de autonomía ${ }^{12}$ que poseen, pueden establecer condiciones que van

11. MERINO, A., La responsabilidad social corporativa: su dimensión...", cit., pág.14: "La dimensión interna de la RSE, que se quiere hacer extensiva a todo tipo de empresas, con independencia de su tamaño y localización, haría referencia a las prácticas responsables que afectan a las actividades que de modo inmediato, sin intermediación, controla la empresa, y que en lo social irían referidas a las condiciones de quienes directamente prestan su fuerza de trabajo para la empresa en cuestión. Desde esta perspectiva y retomando los contenidos laborales de la RSE, éstos se proyectarían sobre las condiciones de los trabajadores de la empresa que quiere instaurar pautas de conducta socialmente responsables: empleo, inserción, formación, igualdad retributiva, conciliación de la vida laboral y familiar, salud laboral..., etc. Debe repararse, a este respecto, en el concepto comúnmente aceptado, conforme al cual, y como se ha visto, la responsabilidad social corporativa integraría un conjunto de prácticas que van más allá del cumplimiento de la ley y de los convenios colectivos. Ello supondría, sin lugar a dudas, que las condiciones de trabajo, al menos hasta donde hayan sido objeto de tratamiento legal y/o convencional, quedarían fuera del marco de la RSE".

12. BEJARANO, A., Principio de la condición más beneficiosa y reglas de absorción, compensación y supresión de la misma. Biblioteca de Derecho laboral, J.M. Bosh editor, Barcelona, 2001, pág. 19: "pertenece al género de los denominados "contratos normados", lo que quiere decir que, una vez celebrado mediante acuerdo entre las partes, automáticamente le resultan aplicables una serie de normas reguladoras sin que los contratantes tengan que hacer una declaración expresa en ese sentido. Esto significa que el campo de actuación reservado a la autonomía contractual individual es bastante reducido pues está en su mayor parte subordinado o predeterminado heterónomamente, tanto por normas de origen estatal como por la normación colectiva". más allá de la ley o convenio colectivo, en algunos asuntos no contemplados en estas normas. La RSE cumple un papel fundamental al darle esencia a esas acciones que van más allá de lo estipulado en la ley o en los convenios mismos, fortaleciendo el modelo de actuación del área de gestión humana, que a su vez incide en el modelo de gestión de la empresa en general.

Todo lo que un trabajador recibe debe tener como finalidad incrementar su calidad de vida en el trabajo, compensar el esfuerzo físico e intelectual que él despliega al realizar su labor; por ello, no es, ni será nunca, conveniente que el empresario -en un momento determinado- tenga fines diferentes a los planteados por la RSE y ofrezca una serie de garantías y beneficios que van más allá de la ley y convenios colectivos, para que sus trabajadores no se sindicalicen.

En el ámbito interno también se encuentran los accionistas, propietarios e inversores, que desean que la empresa obtenga cada día mayores beneficios y pueda ser rentable con el fin de cumplir con su objeto social. La relación de éstos con los trabajadores debe estar enmarcada por el respeto de los derechos humanos y laborales. Igualmente, los administradores son encargados de llevar a la práctica e impulsar la RSE. Es aquí donde la dimensión económica hace llevar a la empresa por los caminos del buen gobierno corporativo, con transparencia, lealtad y honestidad en todas las actuaciones propias de la misma, sin dejar de lado la responsabilidad de lograr beneficios que -en cierta forma- van a contribuir al desarrollo económico, social y medioambiental.

Aunque no suele tenerse en cuenta, es evidente que corresponde también al ámbito interno de la RSE la aplicación de los poderes empresariales de organización y de estructuración de la empresa, los cuales con la globalización se han incrementado. La aplicación socialmente responsable de estos poderes es un terreno que no se ha desarrollado, pero que afecta a opciones discrecionales del empresario que pueden resultar orientadas por la responsabilidad social. Este necesario vector que orienta o dirige la toma de decisiones del empresario en materia de configuración de 
plantilla, reducción de personal o externalización de actividades, por poner solo algunos ejemplos, tiene -si cabe- una aplicación más urgente en épocas de crisis económica, en donde la consideración "social" de la decisión empresarial es extraordinariamente relevante.

Dentro del ámbito interno de la RSE los trabajadores ocupan un lugar destacado e importante en materia de la gestión de los recursos humanos. Este debe contribuir con la realización de buenas prácticas antes de la contratación, durante y después de ella, y en general, en temas como: formación, desarrollo profesional, igualdad de género, igualdad salarial, cualificación profesional, conciliación de la vida laboral, familiar y personal, seguridad en el trabajo, socialización, prácticas responsables de contratación, acceso de minorías a empleos dignos y con calidad, mediante medidas no discriminatorias; entre otras, con las que la empresa debe velar por la permanencia de los mismos y atraer personas cualificadas para su desarrollo profesional y personal, incidiendo en el progreso de una sociedad local, que recibe y asume de forma directa o indirecta, las consecuencias de sus actuaciones.

Todos los grupos de interés de la empresa, ya sea que pertenezcan al ámbito interno o externo, están llamados a cooperar en la construcción de objetivos y metas posibles y medibles, generadoras de progreso, justicia y bienestar. Si la empresa realiza acciones aisladas sin integrarlas a su esencia y a su modelo de gestión y sin estar legitimadas por su gobierno corporativo y por su grupo de interés, difícilmente alcanzará resultados importantes ni llegará ser responsable socialmente. ${ }^{13}$

13. MERINO.A., La responsabilidad social corporativa: su dimensión..., cit., pág. 24: "En efecto, en el entendimiento de que una empresa difícilmente podrá ser considerada socialmente responsable cuando en lo laboral opera con cuestionable responsabilidad al conculcar los derechos de los trabajadores, utilizando, por ejemplo, mano de obra infantil y vulnerando las reglas más esenciales del trabajo, es por lo que resulta coherente 'desechar' determinados contenidos e interpretar que la RSE no es sinónimo de acción social, la RSE no es mecenazgo,

\section{Externa}

Es aquí, en esta dimensión, donde la importancia de la RSE no sólo afecta a la empresa principal sino a las filiales, sucursales, socios comerciales, cadenas de suministro, entre otros, que se encuentran domiciliados en otros países, en su mayoría con legislaciones débiles y mecanismos judiciales y administrativos casi inexistentes. El ámbito externo está correlacionado con las actividades productivas o de servicios que realizan las empresas multinacionales a nivel internacional y su red comercial, que lleva implícita la producción ${ }^{14}$. Las empresas deben asumir el compromiso de respetar los derechos fundamentales en todos y cada uno de los espacios de la cadena productiva y velar por su estricto cumplimiento ${ }^{15}$.

Es por eso que muchos analistas plantean que deben existir unos estándares mínimos que lleven a los Estados al compromiso de cumplir los Convenios de la OIT que hayan ratificado y alcanzar así un sistema laboral fortalecido, con mayor vigilancia e inspección hacia las empresas o centros de trabajo.

Si existieran vacíos por parte de los Estados en la protección de los derechos laborales las

no es filantropía, no es el territorio sustantivo de una fundación, no es una herramienta de marketing y no es un sucedáneo de la negociación colectiva".

14. MERINO, A., Responsabilidad social corporativa: su dimensión..., cit., pág. 9: "La dimensión externa de la RSE afecta no sólo a la empresa matriz, sino también a sus filiales y socios comerciales, fundamentalmente en aquellas actividades caracterizadas por la descentralización y deslocalización productiva. Desde esta inteligencia, el área de actuación de la RSE se extiende básicamente al reconocimiento y promoción de los derechos humanos socio-laborales básicos, muchos de ellos "violados o directamente prohibidos en gran número de países".

15. HERNANDEZ ZUBIZARRETA, J., “¿Lex mercatoria o de derechos humanos? Los sistemas de control de las empresas multinacionales", en AA.VV, El negocio de la responsabilidad. Crítica de la Responsabilidad Social Corporativa de las empresas..., cit., pág18: "Las relaciones laborales en América Latina son otro ejemplo. Las reformas neoliberales efectuadas en el continente latinoamericano transitaron en torno a la flexibilidad, la economía informal y la pérdida de garantías de los derechos laborales individuales y colectivos". 
empresas pueden actuar según su criterio. Esto abre el espacio para cometer abusos o lesionar derechos fundamentales y laborales, sobre todo en aquellos países en vías de desarrollo, donde la informalidad y la desregularización del derecho laboral tienen una mayor incidencia ${ }^{16}$.

La responsabilidad social va también más allá de las fronteras que demarcan territorialmente la empresa, al exigir - de forma directa a los integrantes de toda la cadena de producción de bienes o servicios- el cumplimiento de los derechos laborales y humanos al interior de cada una de las organizaciones.

Debe existir una regulación mundial mínima que funcione como un "marco", en la que las empresas sepan cómo actuar en el desarrollo de las relaciones laborales mundiales. Esto beneficiaría a aquellos países en los cuales no hay normas de derecho positivo que regulen la forma de trabajo, o en los que no se conceden ciertos derechos propios de la relación de trabajo, ya sean individuales o colectivos.

Con relación a los países de América Latina, se evidencia un mayor incumplimiento en las obligaciones legales, especialmente las que tienen que ver con los derechos laborales básicos. Por ello, la figura de los Acuerdos Marco Globales (AMG) puede ser una herramienta jurídico-social de protección, garantía y cumplimiento de los derechos laborales y humanos de los trabajadores en el ámbito mundial.

16. MERINO, A., "Responsabilidad social corporativa: su dimensión...”, cit., pág. 10: "Quizá lo conveniente sería entonces avanzar hacia una responsabilidad jurídica de los gobiernos y de las propias empresas multinacionales, y reservar la RSE para aquellas actuaciones que vayan más allá del cumplimiento de la normatividad estatal, fundamentalmente en aquellos espacios nacionales donde impera una legislación que no reconoce los más esenciales derechos sociales, implicando entonces a las compañías no sólo en las actividades que controlan de modo directo, sino también en relación con toda la cadena de producción, y extendiendo, consecuentemente, el espectro de sus responsabilidades a las acciones desarrolladas por sus filiales, talleres, proveedores, suministradores y contratistas".
En la actualidad son cada vez más las empresas que están acogiendo este tipo de figura, nacida en el seno de los Comités de Empresa Europeos y del sindicalismo internacional. Su implementación colabora en el desarrollo de mecanismos de acción efectivos en espacios regulativos más allá del marco normativo de los Estado-nación y de la propia acción de organismos internacionales especialmente de las ETN.

El sindicalismo mundial ha aportado la formación de reglas sociales con el fin de lograr una incorporación de instrumentos formales más eficaces en la protección de derechos. Los AMG tienen como principal objetivo asegurar, en todas las sedes que tenga la empresa globalizada, los derechos fundamentales que hacen parte del núcleo mínimo de derechos laborales contenidos en la Declaración de 1998 sobre Principios y Derechos Fundamental. Estos son: la libertad sindical, el reconocimiento del derecho a la negociación colectiva, la eliminación de todas las formas de trabajo forzado u obligatorio, la abolición efectiva del trabajo infantil, la eliminación de la discriminación en el empleo y la ocupación ${ }^{17}$.

17. BAYLOS. A., Un instrumento de regulación: Empresas transnacionales y acuerdos marco globales, Cuadernos de Relaciones Laborales, "La responsabilidad social empresarial en Europa y las corporaciones transnacionales, Vol.27, núm.1. UCM, 2009, pág. 114: "Estos fenómenos son ante todo fruto de la transformación y profunda renovación del sindicalismo internacional y europeo, que entiende imprescindible estructurarse organizativamente y desarrollar los mecanismos clásicos de acción en paralelo a los fenómenos de globalización, contrariando la conocida máxima que afirma que el capital se organiza globalmente pero el trabajo sólo lo hace localmente. Por eso va construyendo su acción en los espacios regulativos que se abren más allá del marco normativo del Estado - nación y de la acción de los organismos internacionales, entre ellos y de manera destacada, la empresa transnacional. Pero el sindicalismo globalizado tiene que intervenir en estos procesos de formación de reglas de manera diferente a como lo hace en los sistemas jurídico-laborales estatales y en los organismos internacionales, señaladamente la OIT. Su objetivo en estos casos es el de producir reglas sociales y lograr un desplazamiento de los mecanismos informales de gestión del trabajo hacia instrumentos formales de regulación de éste". 


\section{Principios que orientan la RSE}

El primer principio es el de voluntariedad. Este principio es permanente en todo lo que tiene que ver con la RSE. Es un hecho que nace desde la misma dirección estratégica de la empresa, integrándose a su gestión diaria. A las empresas no se les obliga a ser socialmente responsables, se parte de su propia voluntad de llevar a cabo -desde su gestión- la RSE, teniendo en cuenta a sus stakeholders.

Un segundo y capital principio remite a su carácter universal. Es claro que en el mundo actual, las empresas se deslocalizan o relocalizan en diferentes países. Este fenómeno abre la oportunidad de tener presencia en zonas apartadas y pobres del mundo. Dicha universalidad se traduce en un reto para las mismas empresas, ya que deben llevar a cabo una política mundial de RSE, con parámetros claros, en países en los que los estándares laborales no sean fuertes, o no exista una legislación sólida, con instituciones judiciales o administrativas tradicionalmente consolidadas.

La RSE se caracteriza en sí misma por su principio participativo. La empresa en su política de RSE debe dar participación a los diferentes grupos de interés e integrarlos a su gestión y desarrollo; atender y priorizar sus necesidades y actuar conforme a ello; tener en cuenta los riesgos que puede generar con sus decisiones y minimizarlos. La gestión diaria de la RSE exige que sea participada para conciliar puntos divergentes que pueden surgir. Sin una RSE participada, difícilmente se lograrán resultados positivos.

En definitiva, la RSE debe concebirse como un modelo de gestión para las empresas. Modelo que debe ser participado y no impuesto de forma unilateral por la dirección, ya que en el área interna de la RSE los trabajadores constituyen un grupo de interés, al que se les debe dar participación en el diseño de la política de RSE, así como en su práctica. Todo ello les permite a las empresas crear un modelo de desarrollo social, cultural y de gestión para fortalecer los derechos de los trabajadores, generándoles beneficios.

Las empresas, cuando inician un programa de RSE, deben incluir mecanismos de participación real y efectiva con el fin de contribuir al desarrollo de proyectos que implican intereses de los trabajadores. Cuando ellos son participados, los resultados en los objetivos propuestos son positivos y se avanza con mayor ritmo e interés. ${ }^{18}$

A pesar de que la voluntariedad es un elemento esencial de la RSE, a las empresas se les debe exigir que las iniciativas sean participadas. Si se quiere lograr efectos importantes en la construcción y desarrollo de un modelo social y responsable al interior de la empresa, con resultados demostrables y cuantificables, se hace necesaria, y obligatoria, la participación de los trabajadores.

\section{Conclusiones: retos y desafíos para el Gobierno y actores sociales}

Una de las controversias que más se suscita es cuál es el papel que debe asumir la administración pública en el campo de la RSE, máxime que ella se encuentra obligada a velar para que las empresas cumplan con la normativa vigente nacional que cada país tiene. Lo ideal es crear políticas públicas en torno al tema; estas deben incentivar a las empresas a ir más allá de las normas establecidas y fomentar de esta forma la RSE.

El gobierno podría presentar proyectos de ley que le den vida práctica a la RSE, mediante la exigencia de códigos de conducta propios en las empresas y balances sociales con incidencia en temas como el ambiental, social, económico, entre otros. Pero a su vez, la administración pública podría promover una visión más integral de la RSE y crear una estrategia nacional,

18. ARAGÓN, J., ROCHA, F. y CRUCES, J., "La dimensión laboral de la RSE en España: un análisis... “, cit., pág. 37: "El elemento central que se plantea a la hora de abordar la RSE como proceso, es que todas las iniciativas voluntarias adoptadas por las empresas en materia laboral deberían ser pactadas con los representantes legales de los trabajadores. Es decir, no se cuestiona el carácter voluntario de estas iniciativas; sino que estas sean adoptadas unilateralmente por las empresas sin contar con la participación de los trabajadores en las distintas fases del proceso (elaboración, aplicación y evaluación)". 
con la participación de los diferentes sectores de la sociedad, como podrían ser: instituciones del sector público, las ONG, la academia, los sindicatos y la sociedad civil. Este sería el punto de partida con el fin de llegar a consensos sobre el concepto, alcance y otros aspectos propios de la RSE; es crear un grupo multistakeholders similar al creado en Europa (Forum multistakeholders) o en España (Consejo Estatal en Responsabilidad Social-CERSE-).

El Gobierno puede también, dentro de sus estrategias, fomentar diferentes alternativas en el ámbito de la RSE para las empresas de los diferentes sectores, con énfasis en el eje social, entre las cuales se destacan:

- Creación de incentivos fiscales para aquellas empresas que tengan programas de responsabilidad social con exigencias previamente establecidas.

- Ayudas a las empresas que adopten criterios de responsabilidad social.

- Formación y sensibilización en el tema que abarque tanto al sector público como privado mediante materiales impresos, foros, seminarios, entre otros.

- Reconocimientos y creación de premios con el fin de difundir las buenas prácticas empresariales y estimular su desarrollo.

- Crear canales de comunicación para que los diferentes actores puedan expresarse y permitir que la RSE tenga en cuenta sus diversos criterios. Los eventos que se realicen pueden utilizarse entre otras cosas para promover la ISO 26000 sobre RSE, o si existe alguna otra a nivel nacional.

- Incluir dentro del programa de gobierno, objetivos y metas medibles en el tema de la RSE.

- Incentivar la investigación del tema en las universidades.

- Fomentar alianzas público-privadas que permitan crear herramientas en la implementación y desarrollo de la RSE, así como la adopción de indicadores para medir impactos de los programas en los ámbitos donde se desarrollen, ya sea el interno o externo.

- Hay algunos programas que en el país se realizan en conjunto con instituciones y organismos internacionales. Por ejemplo, el llevado por la OIT y los gobiernos sobre Trabajo Decente, Trabajo Infantil, y otros; a este respecto, podría evaluarse la forma cómo la RSE aporta nuevos contenidos a esos programas, la cual estaría presente de forma transversal en los mismos con la participación de la empresa, gobierno, organizaciones sociales, civiles, entre otros.

\section{Referencias bibliográficas}

ARAGÓN, J., ROCHA, F. y CRUCES, J. (2005) La dimensión laboral de la RSE en España: un análisis de casos, Cuadernos de Información Sindical, La dimensión laboral de la responsabilidad social de las empresas, núm. 63.

BAYLOS, A. (2005) Responsabilidad legal de las empresas transnacionales, Revista de Derecho Social Latinoamericano, núm. 1 .

BAYLOS, A. (2005) Códigos de conducta y buenas prácticas de las empresas en materia laboral. El problema de su exigibilidad jurídica, en Aspectos económicos de la jurisdicción social, CGPJ, Madrid: Editorial Pirámide.

BAYLOS. A. (2009) Un instrumento de regulación: Empresas transnacionales y acuerdos marco globales, Cuadernos de Relaciones Laborales, "La responsabilidad social empresarial en Europa y las corporaciones transnacionales, Vol.27, núm.1. UCM.

BECK, U. (2000) Un nuevo mundo feliz, la precariedad del trabajo en la era de la globalización. Barcelona: Paidós.

BECK, U. (2008) ¿Que es la globalización? Falacias de globalismo, respuestas a la globalización. Barcelona: Paidós.

DAUGAREILH, I. (2009) Responsabilidad Social de las empresas transnacionales: Análisis crítico y perspectiva jurídica, en Cuadernos de Relaciones Laborales, La responsabilidad social empresarial en Europa y las corporaciones transnacionales, Vol.27, núm.1.

ERMIDA, O. (2007) Ponencia de las jornadas proyecto ES$T E R$, COMPTRASEC, Bordeaux, inédito.

Bejarano, A. (2001) Principio de la condición más beneficiosa y reglas de absorción, compensación y supresión 
de la misma. Barcelona: Biblioteca de Derecho laboral, J.M. Bosh editor pág. 19

CERFEDA.W. (2005) El sindicalismo europeo ante la responsabilidad social empresarial, Cuadernos de Información Sindical. La dimensión laboral de la responsabilidad social de las empresas, núm.63.

GUADAMILLAS, F., SANTOS J., ESPINOSA, N. (Coords.), CUADRAO, E., ANDRÉS, M. y VALDÉS, B. (Coods. técnica), AA.VV (2009) La dirección de la empresa responsable. Guía de implementación y buenas prácticas en Castilla-La Mancha, APM Castilla La Mancha, Toledo: Thomson.

HERNÁNDEZ ZUBIZARRETA, J. (2009) Las Empresas Transnacionales Frente a los Derechos Humanos: Historia de una asimetría normativa. De la responsabilidad social corporativa a las redes contrahegemónicas transnacionales, Observatorio de las Multinacionales en América Latina (OMAL) e Instituto de Estudios sobre Desarrollo y Cooperación Internacional, Universidad del País Vasco (HEGOA), Bilbao.

HERNÁNDEZ, J. (2009) ¿Lex mercatoria o de derechos humanos? Los sistemas de control de las empresas multinacionales, en AA.VV., El negocio de la responsabilidad. Crítica de la Responsabilidad Social Corporativa de las empresas transnacionales. Barcelona: Icaria.

JARAMILLO, Isabel (2013) La responsabilidad social empresarial. Base fundamental para el cumplimiento y fortalecimiento de los derechos laborales. Medellín: Editorial Diké.

MERINO, Amparo. (2005) Responsabilidad Social Corporativa: su dimensión laboral, Documentación Laboral, $\mathrm{n}^{\circ} 75$, pp. $51 \mathrm{ss}$.

SANGUINETTI, Wilfredo. (2012) Derecho del trabajo. Nuevos escenarios. San José: Investigaciones jurídicas S.A.

\section{Instituciones y organismos internacionales}

\section{COMISIÓN DE LA COMUNIDADES EUROPEAS:}

Libro Verde, Fomentar un marco europeo para la responsabilidad social de las empresas [COM (2001) 366 final], Bruselas, 18.7.2001.

Comunicación al Parlamento Europeo y al Comité Económico y Social, Promover las normas fundamentales de trabajo y mejorar la gobernanza social en el contexto de la mundialización [COM (2001) 416 final-no publicada en el Diario Oficial], Bruselas, 18.7.2001
Comunicación relativa a "La responsabilidad social de las empresas: una contribución empresarial al desarrollo sostenible" [COM (2002) 347 final], Bruselas, 2.7.2002.

Comunicación de la Comisión al Parlamento Europeo, al Consejo Europeo y al Comité Económico y Social Europeo, Poner en práctica la asociación para el crecimiento y el empleo: hacer de Europa un polo de excelencia de la responsabilidad social de las empresas [COM (2006)136 final], Bruselas, 23.03.06.

Comunicación de la Comisión, "Estrategia renovada de la UE para 2011-2014 sobre la responsabilidad social de las empresas [COM (2011) 681 final], Bruselas 25.10.2011.

INSTITUTO URUGUAYO DE NORMAS TÉCNICAS. UNIT-ISO 26000:2010. "Guía de Responsabilidad Social” (ISO 26000:2010, IDT). Montevideo, 2010.

OCDE:

Lineas Directrices para Empresas Multinacionales de la OCDE, 2000.

OIT:

Declaración de la Organización Internacional del Trabajo relativa a los principios y derechos fundamentales en el trabajo, 1998 .

\section{PARLAMENTO EUROPEO:}

Resolución sobre la Adopción de normas por la Unión Europea para las empresas europeas que operan en países en desarrollo: Hacia un código de conducta europeo. A40508/1998, Estrasburgo, 15-1-1999.

Resolución del Parlamento Europeo, sobre La responsabilidad social de las empresas: una nueva asociación, [2006/2133(INI)], Estrasburgo, 13-3-2007.

Resolución del Parlamento Europeo, sobre "la responsabilidad social de las empresas de subcontratación en las cadenas de producción" ((2008/2249 (INI)). Bruselas 26.3.2009.

\section{UN. GLOBAL COMPACT}

Guía del Pacto Global, una forma práctica para implementar los nueve principios en la gestión empresarial, 2004. Dirección electrónica: http://wwwunglobalcompact.org Revisado por última vez: 21 setiembre, 2014. 
